\title{
8
}
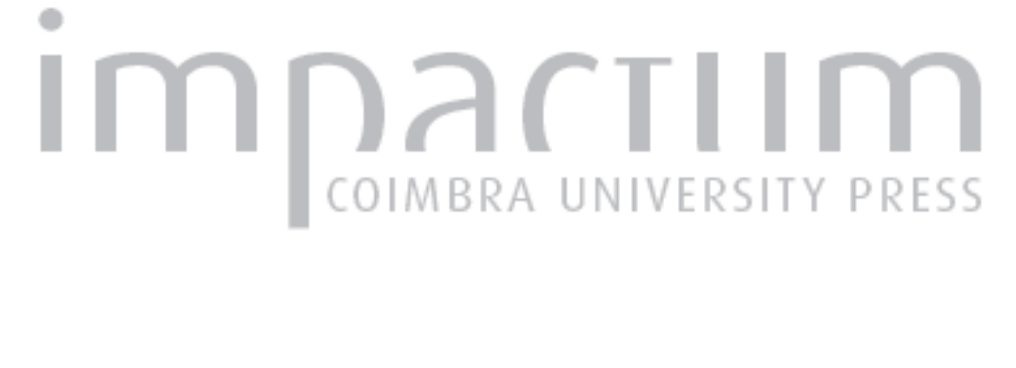

\section{A perceção da insegurança na cidade de Coimbra}

\author{
Autor(es): \\ Vaz, Ana Maria Cortez; Barros, Cristina Faria; Fernandes, João Luís \\ Jesus
}
Publicado por: Faculdade de Letras da Universidade de Coimbra, Departamento de Geografia

URL

persistente:

URI:http://hdl.handle.net/10316.2/30218

DOI:

DOI:http://dx.doi.org/10.14195/0871-1623_31_16

Accessed : $\quad$ 26-Apr-2023 13:51:14

A navegação consulta e descarregamento dos títulos inseridos nas Bibliotecas Digitais UC Digitalis, UC Pombalina e UC Impactum, pressupõem a aceitação plena e sem reservas dos Termos e Condições de Uso destas Bibliotecas Digitais, disponíveis em https://digitalis.uc.pt/pt-pt/termos.

Conforme exposto nos referidos Termos e Condições de Uso, o descarregamento de títulos de acesso restrito requer uma licença válida de autorização devendo o utilizador aceder ao(s) documento(s) a partir de um endereço de IP da instituição detentora da supramencionada licença.

Ao utilizador é apenas permitido o descarregamento para uso pessoal, pelo que o emprego do(s) título(s) descarregado(s) para outro fim, designadamente comercial, carece de autorização do respetivo autor ou editor da obra.

Na medida em que todas as obras da UC Digitalis se encontram protegidas pelo Código do Direito de Autor e Direitos Conexos e demais legislação aplicável, toda a cópia, parcial ou total, deste documento, nos casos em que é legalmente admitida, deverá conter ou fazer-se acompanhar por este aviso.

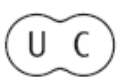




\title{
A perceção da insegurança na cidade de Coimbra
}

\author{
Ana Maria Cortez Vaz \\ Mestre em Geografia Humana, Ordenamento do Território e Desenvolvimento, pela Faculdade de Letras da Universidade de Coimbra. \\ ana_cortezvaz@hotmail.com
}

\section{Cristina Faria Barros}

Mestre em Geografia Humana, Ordenamento do Território e Desenvolvimento, pela Faculdade de Letras da Universidade de Coimbra. cristinabarros1@hotmail.com

\section{João Luís Jesus Fernandes}

Departamento de Geografia e Centro de Estudos de Geografia e Ordenamento do Território (CEGOT). Faculdade de Letras da Universidade de Coimbra. jfernandes@fl.uc.pt

\section{Resumo:}

Os mais recentes dados estatísticos apontam para o aumento da sensação de insegurança em Portugal. Este facto será mais visível nas cidades levando à construção de áreas urbanas mais fragmentadas sob o ponto de vista social e económico, que criam, quase sempre, uma cidade mais desconfortável e menos confiável.

A Nova Geografia Cultural analisa a relação das pessoas com os espaços, e como essas imagens condicionam os comportamentos e as territorialidades das populações. A imagem mental de determinado território deriva das opiniões de amigos, familiares, vizinhos e das mensagens veiculadas por meios de comunicação social que vão associando casos de criminalidade e violência a determinados lugares.

Este texto analisa os resultados de inquéritos efetuados a um universo da população da cidade de Coimbra, que analisam a imagem de (in) segurança da cidade e o modo como esta população condicionou a respetiva territorialidade a esta perceção.

Palavras-Chave: Geografia da Perceção. Geografia da (In) Segurança. Topofilia/Topofobia. Criminalidade Urbana.

\section{Resumé:}

La perception de l'insécurité dans la ville de Coimbra

Les statistiques les plus récentes soulignent l'augmentation du sentiment d'insécurité au Portugal. Ce phénomène sera plus visible dans les villes qui mènent à la construction de zones urbaines plus fragmentées du point de vue social et économique, qui créent, presque toujours, une ville peu accueillante et moins fiable.

La Nouvelle Géographie Culturelle analyse la relation entre les personnes et les espaces, et la façon dont les images influencent le comportement et la territorialité des populations. L'image mentale d'un territoire advient de commentaires d'amis, famille, voisins et de messages véhiculés par les médias qui associent certains cas de criminalité et de violence à certains endroits.

Ce document analyse les résultats des enquêtes menées auprès d'une population de la ville de Coimbra et traduit l'image de (in) sécurité de la ville et la façon dont cette population a conditionné la respective territorialité.

Mots-clés: Perception de la géographie. Géographie de (In) sécurité. Topophilie / topophobia. La criminalité urbaine.

\section{Abstract:}

The perception of the insecurity in the city of Coimbra

The most recent statistics point to the increased sense of insecurity in Portugal. This will be more visible in cities leading to the construction of urban areas more fragmented under the terms of social and economic that creates, almost always, a city more uncomfortable and less reliable.

The New Cultural Geography looks at the relationship between people and spaces, and how these images influence behavior and territoriality of populations. The mental image of a territory derives from reviews from friends, family, neighbors and the messages conveyed by media ranging from cases involving crime and violence in certain places. 
This paper analyzes the results of surveys carried out to a world population of the city of Coimbra that analyzes the image of (in) security of the city and how this population conditioned the relevant technical territoriality to this perception.

Keywords: Perception of Geography. Geography of (In) Security. Topophilia / topophobia. Urban Crime.

\section{Introdução}

O número de vítimas de crimes urbanos tem vindo a crescer. As estatísticas provam-nos e os meios de comunicação social enfatizam esta questão que tem provocado nas cidades o aumento da insegurança e o receio de vitimização.

A integração deste trabalho no âmbito da Geografia Cultural faz-se no sentido em que esta corrente geográfica interessa-se cada vez mais pelas perceções, não só do coletivo, mas também a perceção que cada indivíduo tem de um determinado espaço.

Pondo de lado os mecanismos positivistas, a Geografia Cultural, mais particularmente a vertente da Geografia da Perceção, preocupa-se com as relações Homem-Meio, com as perceções que os indivíduos têm dos lugares, mais próximos ou mais distantes. Esta abordagem, privilegiando o que cada individuo pensa e perceciona vai apoiar-se nas imagens mentais que cada individuo cria sobre um determinado espaço.

A criação de imagens mentais é inerente a cada ser humano e vai condicionar em grande parte a tomada de decisões, os comportamentos, as deslocações, o frequentar ou não determinados espaços.

0 aumento de sentimentos ligados à insegurança resulta fundamentalmente das diversas opiniões de amigos, familiares, vizinhos e até dos meios de comunicação social que vão divulgando casos de criminalidade e violência em determinados locais. Estas influências vão contribuir para enriquecer a imagem mental do indivíduo, levando frequentemente à criação de topofobias (TuAN, 1980), isto é, a criação de imagens negativas e desagradáveis de determinados locais

O presente trabalho debruça-se sobre esta temática, explorando a perceção da população de Coimbra acerca do aumento da criminalidade e da insegurança. Procura-se avaliar quais são as áreas percecionadas como de maior insegurança, e se de algum modo são consideradas repulsivas e evitadas.

\section{Cidades, insegurança e fragmentação do espaço}

Pela leitura dos diferentes meios de comunicação social, fica-se com a sensação que a criminalida- de urbana tem vindo a aumentar, facto que resulta no crescimento dos sentimentos de insegurança e medo. A construção destas imagens mentais, tema ao qual a Geografia tem dedicado atenção, acaba por territorializar-se em comportamentos geográficos muito concretos, que passam pelas opções em domínios da vida social como o lugar de residência, de lazer, de exercício das atividades económicas ou tão só de passagem e circulação. Com efeito, os mapas mentais, para além de inerentes a cada ser humano, vão condicionar a tomada de decisões, os comportamentos, as deslocações, a presença ou não em determinados espaços geográficos.

A construção das imagens mentais de um lugar é complexa e passa por múltiplos fatores. No que diz respeito à sensação de insegurança, são relevantes as opiniões de amigos, familiares, ou vizinhos que, a partir de leituras pessoais também estas muitas das vezes já condicionadas por outras fontes de influência, acabam por ser indutoras de comportamentos territoriais. Neste jogo entram ainda os conteúdos e os meios de divulgação dos mesmos com origem na comunicação social, escrita e/ou visual. Sendo a criminalidade um tema mediático, os meios de comunicação de massas, enquanto instrumentos de construção de opiniões, surgem na primeira linha da modelação da imagem de (in) segurança de cada lugar.

Estas múltiplas influências vão contribuir para adensar a imagem mental do indivíduo, levando frequentemente à criação de topofobias (TUAN, 1980), isto é, de imagens negativas e desagradáveis de determinados locais.

Um dos principais focos desta crescente vigilância defensiva face a lugares que, assim é veiculado pelas principais representações, se terão tornado mais perigosos e violentos, têm sido os espaços urbanos. Assim se retoma o discurso da cidade enquanto território de risco, em especial nos modelos de expansão urbana que levaram ao crescimento destas sem o devido acompanhamento das estruturas físicas e sociais que garantam urbanidade e a consequente qualidade de vida. Este debate é relevante em cidades de maior dimensão demográfica e ritmos mais pronunciados de crescimento por dinâmicas de chegada de novos residentes sem as estruturas físicas, económicas e sociais ideais para uma boa integração. Assim se expandem os microterritórios 
mais degradados e se constrói uma cidade social e economicamente mais fragmentada, facto que, no limite, segundo Rogério HaESBAERT (2004), pode conduzir levar à construção de "aglomerados de exclusão" numa cidade que se torna assim mais desconfortável e, questão grave na estratégia de qualquer lugar, menos confiável. A estre propósito, como refere GASPAR (1987: 120) "a falta de resposta às necessidades de espaço das classes mais desfavorecidas constitui também uma forma de promover a segregação". Da segregação social à fragmentação do espaço vai um caminho estreito que sublinha as (novas) fronteiras no interior de espaços urbanos que, apesar da expansão do construído, se tornam menos cidade.

Num discurso também este com alguns riscos ideológicos, assim se apontam os recém chegados à cidade, os imigrantes, os bandos juvenis de contra-cultura, os toxicodependentes ou os mais pobres como atores urbanos que, pelo afastamento a uma média social (numa aparência nem sempre confirmada pelos factos) associada à segurança e à previsibilidade, se tornarão também mais vulneráveis e menos resistentes aos caminhos da criminalidade. Nesse sentido, a marca de microterritórios urbanos passa também pela perceção de filiação dos mesmos a subgrupos de uma população urbana complexa e diversificada.

São vários os autores (Esteves, 1995; Ferreira, 1998; Wikström, 2000; Felix, 2002; Bauman, 2006) que confirmam a maior incidência do crime nas áreas urbanas em relação às áreas rurais, associando-se este facto a razões como a existência de um maior número de focos de pobreza nas áreas urbanas.

No essencial, a pobreza assume particular relevância e características muito próprias nos espaços urbanos, onde é maior a pressão demográfica, proliferam os bairros degradados e de habitação social, o consumo e tráfico de droga, as maiores taxas de desemprego, situações de exclusão social, o crime e, em especial, o medo do crime.

Como argumenta WıKSTRÖM (1990), existirá uma forte relação direta e proporcional entre a criminalidade e o crescimento urbano, sendo este último um fator de potencialização dos conflitos sociais.

Contudo, para além da morfologia da dimensão, também qualidades urbanas como a requalificação dos espaços públicos, as densidades, os espaços verdes, a mobilidade espacial, os instrumentos de participação e empowerment económico e sociocultural ou a qualidade da habitação influenciam o grau de criminalidade. Ainda assim, quanto maior o número de pessoas, maior a frequência de contactos entre desconhecidos e maio-

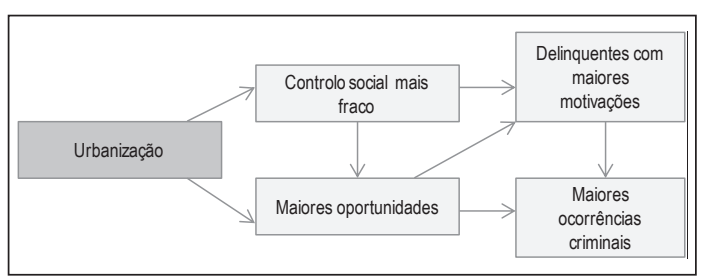

Figura 1

Relação entre a Urbanização e o aumento da criminalidade.

Fonte: Adaptado de WIKSTRÖM, 1990.

res as oportunidades que se geram para a prática de atos delinquentes (Figura 1).

A heterogeneidade característica das áreas urbanas, a coexistência espacial de atores com diferentes graus de poder político, com diferenças económicas, sociais e étnicas é vista como um elemento potenciador das práticas criminais. O agravamento das condições socioeconómicas dos delinquentes, assim como a perceção da sua condição de marginalidade e desigualdade relativamente a outros segmentos da sociedade, vai conduzir ao aumento de comportamentos desviantes, que se irão traduzir no aumento de crimes contra as pessoas e no aumento da perceção de insegurança por toda a comunidade. A estes fatores acrescentam-se outros que se associam às políticas de construção da cidade, em muitos casos definindo áreas-sombra, corredores marcados pela velocidade, espaços que, a determinadas horas e em determinadas circunstâncias, se tornam territórios de poucos e lugares com difícil regulação das práticas sociais. Em muitos casos, a compensação destas ausências através de sistemas eletrónicos de vigilância à distância não tem sido suficiente.

\section{Geografia, perceção e construção de imagens mentais}

O modo como as pessoas leem o espaço, os sentimentos que desenvolvem, as formas como se organizam e apropriam o espaço, determinam uma geometria sócio espacial com fronteiras bem definidas que sobressaem no mosaico urbano, criando unidades não permeáveis isoladas por razões sociais, económicas e culturais - os espaços dos "muito ricos e dos muito pobres, os subúrbios e os bairros de lata, os guetos raciais e de imigrantes" (FELIX, 2002).

A perceção ambiental é o modo através do qual os indivíduos apreendem o seu ambiente, facto que é a resultante da avaliação e armazenamento de informações sobre estes espaços. Este conceito, associado 
a uma corrente humanista do pensamento geográfico (TuAn, 1980), acrescenta complexidade às perspetivas mais positivistas dominantes no pós II Guerra Mundial.

Como contraponto a este esquematismo, a Geografia da Perceção sugere que os indivíduos não agem como meros "homens económicos"1 uma vez que, enquanto seres complexos, a sua perceção ambiental nem sempre corresponde à realidade objetiva.

$\mathrm{Na}$ escola da perceção é possível destacar duas correntes, uma inspirada no positivismo e Kantismo, a "escola behaviorista" e outra com fortes ligações ao humanismo. Para os behavioristas, a perceção do ambiente tem importância fundamental, pois é a partir dela que os indivíduos tomam decisões em relação à sua vivência no espaço. Da escola humanista, centrada na perceção, criatividade, experiência e valores humanos, salienta-se o trabalho do geógrafo Yi-Fu Tuan, que introduz alguns conceitos importantes. Segundo Tuan (1980), a topofilia representa o sentimento de afeição em relação ao espaço, "um elo afetivo entre a pessoa e o lugar ou ambiente físico". Em oposição, a topofobia representa a aversão a determinados lugares. A perceção é fundamental no processo de construção de topofilias e topofobias, representando tanto uma resposta mecânica dos sentidos aos estímulos externos, como uma atividade auto controlada, na qual certos fenómenos são ressaltados e registados, enquanto outros preteridos ou totalmente bloqueados (Tuan, 1980).

No quadro urbano, a topofobia gera imagens desagradáveis de determinados lugares. Assim se constrói o contraste muito comum nas cidades, marcadas por uma imagem positiva e agradável das áreas economicamente mais prósperas, e uma imagem negativa e desagradável dos locais que apresentam maiores privações. Os lugares mais pobres vão criar sentimentos de medo e insegurança, tornando esses espaços repulsivos ou pouco frequentados pela maior parte da população. Neste ponto de vista há que ter em conta dois aspetos: a escala geográfica e o indivíduo/grupo humano considerado. Com efeito, a imagem topofóbica da cidade pode ser assumida pelo coletivo, como ocorre, por exemplo, com bairros onde ocorrem altos índices de criminalidade, que criam aversão por parte da maioria da população. Essa imagem negativa pode também ser um caso individual, aqui mais relacionado com lugares pequenos, como uma rua, um prédio, uma casa que, por qualquer

${ }^{1}$ Algumas correntes da ciência económica assumiram que o estudo das ações económicas do homem poderia ser feito abstraindo-se as outras dimensões do comportamento humano, como as morais, as éticas, as religiosas ou as políticas, concentrando o seu interesse no que se identificou como as duas funções elementares exercidas por todo e qualquer indivíduo - o consumo e a produção. razão, representa uma geografia afetiva repulsiva para esta ou aquela pessoa (KASHIWAGI, 2002).

No entanto, a realidade que se percebe é condicionada pelos valores do observador, uma vez que a perceção do espaço é muito influenciada pelos padrões culturais nos quais estão inseridos os indivíduos.

Segundo Tuan (1980), um ser humano percebe o mundo através de uma complexa conjugação de todos os sentidos - visão, audição, olfato, paladar e tato - levando a uma apreensão multissensorial do espaço.

0 mundo percebido pode ser imaginado a partir de estímulos exteriores, pois a filtragem de origem cultural ou, até mesmo, pessoal pode evocar diferentes imagens do mundo real. No processo de perceção do meio ambiente, a Fenomenologia ${ }^{2}$ permite desvendar o mundo percebido e o vivido do homem e mostrar que os seres humanos compartilham perceções comuns, em virtude de possuírem órgãos similares. Segundo Esteves (1995), "uma parcela da nossa visão é bastante particular, enquanto outra parte é partilhada ou tida em comum com outras pessoas". No entanto, para analisar as relações do Homem com o meio ambiente, é fundamental compreender como se estrutura esse espaço percebido na mente das pessoas, ou seja, como se constroem as imagens mentais.

Não obstante os indivíduos partilharem perceções comuns, a imagem mental é acima de tudo idiossincrática, isto é, cada um de nós possui uma imagem única e exclusiva dentro de si, não só porque vivemos e nos movimentamos em espaços diferentes, mas sobretudo porque cada um tem o seu modo de observar o mundo que nos rodeia. Pela sua formação educacional e intelectual, algumas pessoas estão mais atentas aos objetos físicos, móveis ou fixos, existentes nas ruas, outras aos peões que circulam, e outras são mais sensíveis ao ambiente que aí se vive (ESTEVES, 1995).

A imagem mental resulta de duas fontes de informação: o meio que envolve o Homem (apreendido pelos seus sentidos), e as fontes indiretas de informação, constituídas pelas conversas, opiniões de familiares, amigos e vizinhos ou pelas mensagens veiculadas pelos meios de comunicação social.

Assim, o indivíduo vai adquirir, codificar e descodificar a informação que recebe, formando uma imagem e juízos de valor que o irão guiar na tomada de decisões geográficas, definindo as suas territorialidades (Figura 2).

${ }^{2}$ A Fenomenologia, nascida na segunda metade do século XIX a partir das análises de Franz Brentano sobre a intencionalidade da consciência humana, trata de descrever, compreender e interpretar os fenómenos que se apresentam à perceção. Propõe a extinção da separação entre "sujeito" e "objeto", opondo-se ao pensamento positivista do século XIX. 
Sobretudo a partir dos anos 60, a mente humana, onde se forma a imagem sobre o espaço e onde as decisões são tomadas, torna-se num novo campo de investigação geográfica fundamental para compreender a relação Homem-Meio, uma vez que o comportamento espacial resulta muito das imagens mentais (Esteves, 2002).

Enquanto circunstâncias e fatores condicionantes da formação de imagens mentais intervêm variáveis que vão desde a idade e sexo, passando pela educação e aprendizagem ao longo da vida, pela situação sócio profissional e pelas influências que amigos, familiares vizinhos e meios de comunicação social exercem sobre nós.

$A$ idade de uma pessoa e o seu género ligam-se de uma forma muito direta à situação perante o traba- lho (Esteves, 1995). Um estudante, uma doméstica, um ativo, um reformado vêm o mundo de modo diferente porque fazem deslocações diferentes (escola, lojas, trabalho, jardins). Também a sensibilidade a determinadas situações é distinta entre homens e mulheres, por razões de ordem cultural e psicológica. São habitualmente as mulheres e os idosos, no geral de rendimentos mais baixos, os mais pessimistas em relação ao aumento da criminalidade, dado que se manifesta nos padrões de comportamento, ao evitar frequentar determinados espaços.

A situação profissional das pessoas é um dos principais fatores que influenciam as imagens mentais, na medida em que a atividade que exercem e o correspon-

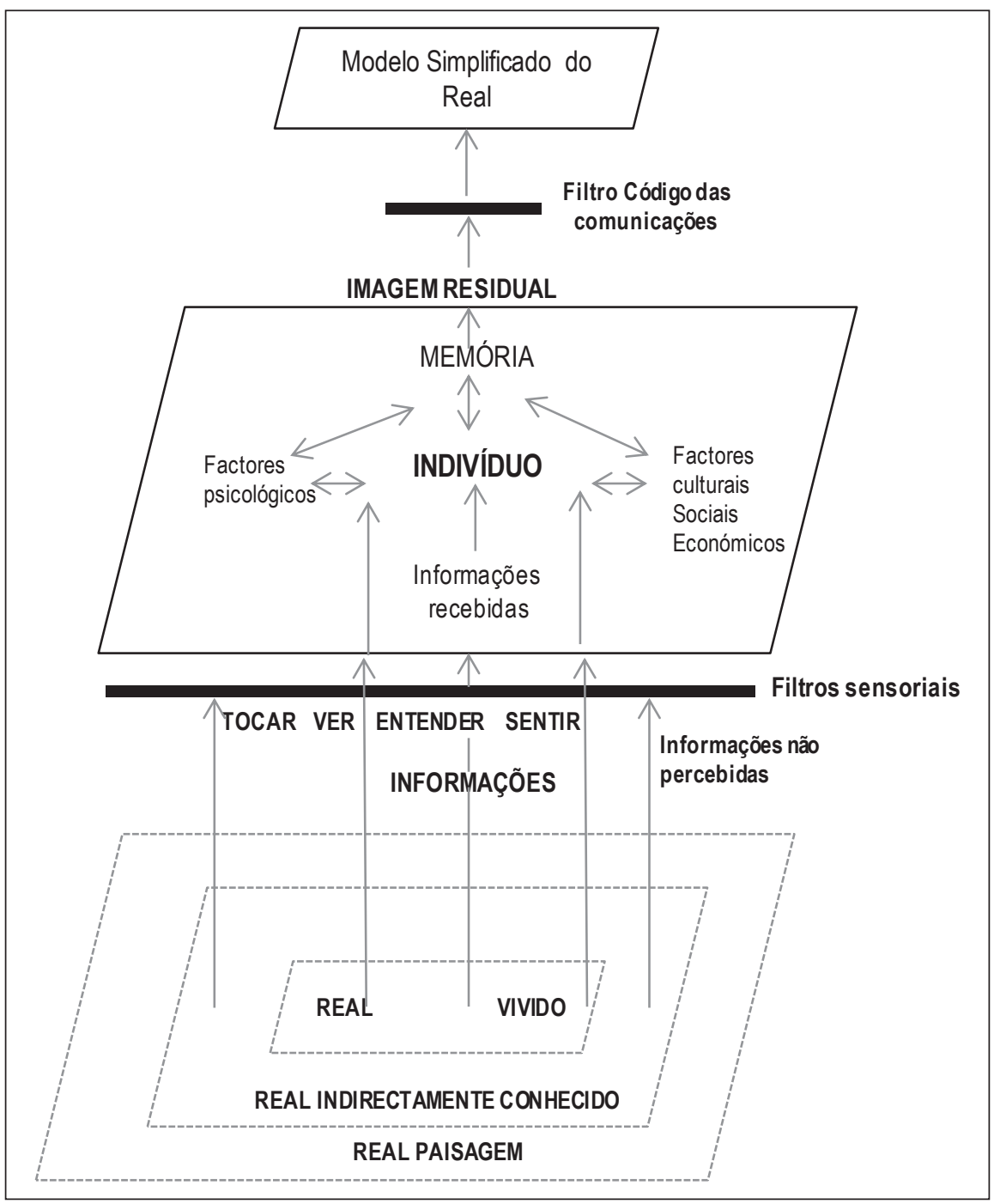

Figura 2

Processos de perceção.

Fonte: Esteves, 2002 (adaptado de Bailly, 1977). 
dente capital de mobilidade thes condiciona a frequência e duração das deslocações pelo espaço público.

Também o grupo socioeconómico, o nível cultural e o local de residência são importantes, visto que vão influenciar o acesso à quantidade e qualidade da informação.

Ao nível da informação transmitida salientamos os meios de comunicação como importantes fatores na formação das imagens mentais. Na verdade, muito do que sabemos do mundo que nos rodeia é nos dado a conhecer pela TV, rádio, jornais, internet, com fontes mais ou menos sensacionalistas que vêm influenciar as imagens mentais dos indivíduos e fomentar sentimentos. É o que faz, por exemplo, o canal de televisão TV Record, ao mostrar cenas de violência e criminalidade no Brasil, criando sentimentos de medo e insegurança para os residentes e recriando imagens negativas e de repulsão para eventuais turistas, moradores ou investidores. Como refere IMBERT (1992) "os meios de comunicação, pelo seu potencial de irradiação, reforçam a sensação de insegurança".

Com base nesta discussão, percebe-se que a Geografia da Perceção traz subsídios importantes para a análise do sentimento de insegurança, introduzindo conceitos e modelos de comportamento que ajudam a identificar e explicar os fatores que levam ao receio e medo de vitimação.

\section{A perceção da insegurança e a imagem da cidade}

Diversos autores (Ferreira, 1998; Bauman, 2006) definem a insegurança como um conjunto de manifestações de inquietação, de perturbação ou medo associados ao crime, isto porque, segundo FerReIRA (1998), o crime atinge os indivíduos na vertente mais íntima e profunda, ligada ao seu corpo mas também à casa e outros bens patrimoniais, acrescentando-se ainda o direito à liberdade de movimentos.

A insegurança, o medo e a ansiedade resultam de um mal-estar, de desconfiança em relação a um local percecionado como perigoso para frequentar, residir ou até mesmo circular. Esta perceção resulta fundamentalmente das diversas opiniões de amigos, familiares, vizinhos e até dos meios de comunicação social que vão divulgando casos de criminalidade e violência em determinados locais, facto que irá contribuir para formar e enriquecer a imagem mental do indivíduo sobre determinado espaço. De acordo com Felix (2002), "esta perceção é dinâmica, altera-se com os valores morais e sociais da população, conforme as suas características e medos, podendo ser avaliada através da análise histórica de um espaço e de uma Sociedade".

Segundo EsteVEs (1995), as consequências sociais que resultam da insegurança, como o receio de circular e ser atacado, não são de negligenciar. Segundo esta autora, ocorre habitualmente uma deterioração na qualidade e na frequência dos contactos sociais e uma perda do sentimento pertença à comunidade, devido à desconfiança em relação quer aos vizinhos, quer aos desconhecidos.

De acordo com Rico e Salas (1998) (cit. Esteves, 2002), podem apontar-se quatro fontes de medo em relação ao crime. A primeira é a perceção do aumento da criminalidade violenta; a segunda reside em experiências pessoais ou com pessoas próximas; a terceira está associada às informações difundidas pelos meios de comunicação social; e a quarta prende-se com um sentimento de insatisfação em relação ao sistema penal. A estes fatores, Esteves (2002) acrescenta um quinto, que se prende com os indicadores do meio envolvente, que se resume ao conjunto de sinais que levam os habitantes de uma área a sentirem-se inseguros e desprotegidos, e que podem agrupar-se em três conjuntos: condições de habitação (ex. degradação física dos edifícios); comportamentos sociais condenáveis e grau de coesão entre os vizinhos.

A perceção espacial pode inverter-se no tempo e modificar as funções de certos espaços (FeLIX, 2002). É o que acontece com as áreas centrais das grandes cidades portuguesas, que mudam completamente de função no decorrer do dia, sendo temidas e evitadas à medida que se aproxima a noite. Aqui refira-se a sazonalidade do espaço, na medida em que um mesmo lugar pode ser frequentado por milhares de pessoas durante o dia, tornando-se despovoado, repulsivo e até temido durante a noite. Em horas diferentes, a apropriação do mesmo espaço faz-se por grupos diferentes, com motivações diferentes.

A perceção do problema criminal não apenas modifica os hábitos dos indivíduos, mas também limita os seus movimentos e provoca atitudes de defesa e proteção. As reações dos cidadãos cuja perceção da insegurança é elevada, vão desde a supressão de determinadas atividades em determinados espaços, o evitar de alguns trajetos, a colocação de alarmes, o reforço de fechaduras, em suma, alterações nos hábitos de forma a reduzir a exposição pessoal ao crime. As atitudes de defesa e proteção irão provocar a limitação de determinados movimentos, originando uma perda de liberdade.

Segundo Santana e Roque (2007), o medo do crime pode ter consequências ainda mais profundas que a própria vitimação, influenciando os indivíduos a alterar as rotinas diárias, e aumentando os níveis de ansiedade 
e nervosismo. Esses estados emocionais podem comprometer estilos de vida saudáveis como caminhar, utilizar largos, praças e jardins, bem como o relacionamento com vizinhos e familiares, com impactes negativos na qualidade de vida, na sua saúde física e em alterações do estado emocional.

Em suma, a perceção da insegurança é diferencial e assume dimensões sociais diversas conforme o ambiente, o estatuto socioeconómico, os instrumentos de informação, a idade e o sexo. Muitas vezes circunscrito a determinados pontos das cidades, como as áreas centrais, os bairros de lata e bairros sociais, o sentimento da insegurança vai provocar níveis de concentração em determinadas áreas e vai criar espaços de medo noutras.

A perceção da insegurança pelas pessoas é o principal fator de rejeição residencial, constituindo um fator decisivo para a escolha do local de residência.

\section{A Perceção da (In)segurança na cidade de Coimbra}

Para observar a perceção da população sobre a insegurança na cidade de Coimbra, realizaram-se inquéritos dirigidos a este universo demográfico. Estes pretenderam abarcar questões pertinentes sobre os lugares onde as pessoas se sentem inseguras, os lugares que, por questões de segurança, evitam, e a perceção geral sobre a insegurança na cidade de Coimbra.

Para tal realizaram-se 100 questionários, dos quais trinta e três dirigidos a jovens, trinta e dois a adultos e trinta e cinco a idosos.

Estes inquéritos foram aplicados no mês de Janeiro de 2012, em diferentes períodos do dia e em locais da cidade distintos como a Baixa, Bairro Norton de Matos, Vale das Flores, Solum e Universidade.

A análise dos inquéritos terá em consideração os vários grupos etários, para se saber se a idade condiciona ou não a perceção desta realidade.

No final, apresentam-se dois cartogramas, o primeiro evidencia os locais de ocorrência de crimes sofridos pela população inquirida, e o segundo descreve as áreas consideradas como mais problemáticas, ou seja, as áreas que os inquiridos percecionam como sendo as mais inseguras.

\subsection{Análise aos inquéritos realizados. A imagem de Coimbra vista por quem frequenta este espaço geográfico}

No sentido de percecionar os sentimentos de insegurança consoante a idade dos inquiridos, os inquéri-
Quadro I

Avaliação da (In) segurança na Cidade de Coimbra

\begin{tabular}{|c|c|c|c|c|c|c|c|}
\hline \multicolumn{7}{|c|}{ "Considera Coimbra uma Cidade Insegura?" } \\
\hline \multirow{2}{*}{ Respostas } & Jovens & \multicolumn{2}{|c|}{ Adultos } & \multicolumn{2}{|c|}{ Idosos } & Total \\
\cline { 2 - 8 } & $\mathrm{N}^{\circ}$ & $\%$ & $\mathrm{~N}^{\circ}$ & $\%$ & $\mathrm{~N}^{\circ}$ & $\%$ & $\mathrm{~N}^{\circ}$ \\
\hline Sim & 15 & 26,8 & 18 & 32,1 & 23 & 41,1 & 56 \\
\hline Não se sim, em que medida?" \\
\hline & 18 & 40,9 & 14 & 31,8 & 12 & 27,3 & 44 \\
\hline Extremamente insegura & 0 & 0 & 3 & 16,7 & 0 & 0 & 3 \\
\hline Muito insegura & 2 & 13,3 & 2 & 11,1 & 4 & 17,4 & 8 \\
\hline Insegura & 9 & 60,0 & 10 & 55,6 & 9 & 39,1 & 28 \\
\hline Pouco insegura & 4 & 26,7 & 3 & 16,7 & 10 & 43,5 & 17 \\
\hline
\end{tabular}

tos foram divididos em três grupos. Assim, para o grupo etário dos jovens, que compreende inquiridos entre os 20 e os 29 anos, efetuaram-se 33 inquéritos; para os adultos, inquiridos entre os 30 e os 59 anos, fizeram-se 32 inquéritos, e para os idosos, com idade superior a 60 anos, realizaram-se cerca de 35 inquéritos.

Em relação ao grupo dos jovens, os indivíduos que acederam responder à realização do inquérito, 18 são do sexo masculino e 15 do sexo feminino. Dos inquiridos adultos, 15 são do sexo masculino e 17 do sexo feminino e dos idosos, 15 são do sexo masculino e 20 do sexo feminino. Em relação à primeira questão, que consistia em saber se os inquiridos consideram Coimbra uma cidade insegura, as respostas encontram-se expressas no Quadro I.

Da análise do Quadro I salienta-se a opinião dos idosos, sendo que $41,1 \%$ destes considera a cidade como insegura. Por outro lado, cerca de $32 \%$ dos adultos e $26,8 \%$ dos jovens inquiridos são da opinião que Coimbra é uma cidade insegura. Quanto à "quantificação" da insegurança, na qual "repartimos" o termo insegurança em extremamente insegura, muito insegura, insegura ou pouco insegura, a classe que mais considera estarmos perante uma cidade extremamente insegura é a dos adultos. Cerca de $17 \%$ dos adultos inquiridos consideram Coimbra uma cidade extremamente insegura.

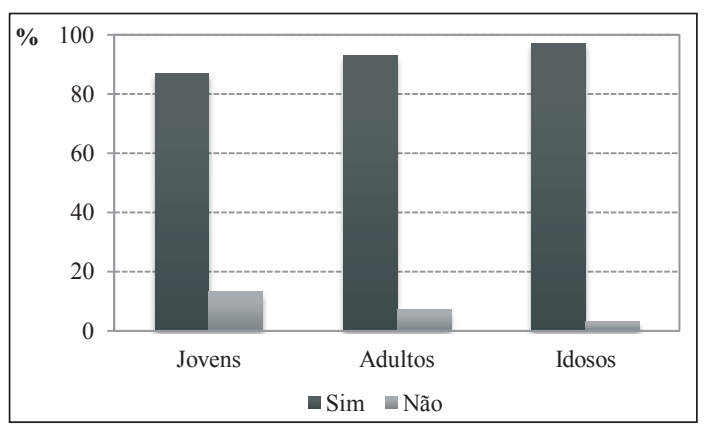

Figura 3

Perceção do aumento da Insegurança na Cidade de Coimbra. 
Quadro II

Opinião sobre sensação de insegurança durante os vários períodos do dia

\begin{tabular}{|c|c|c|c|c|c|c|}
\hline \multirow{2}{*}{ Período do dia } & \multicolumn{2}{|c|}{ Jovens } & \multicolumn{2}{c|}{ Adultos } & \multicolumn{2}{c|}{ Idosos } \\
\cline { 2 - 7 } & $\mathbf{N}^{\circ}$ & $\%$ & $\mathrm{~N}^{\circ}$ & $\%$ & $\mathrm{~N}^{\circ}$ & $\%$ \\
\hline Manhã & 0 & 0 & 0 & 0 & 1 & 2,9 \\
\hline Tarde & 0 & 0 & 3 & 9,4 & 5 & 14,3 \\
\hline Noite & 21 & 63,6 & 26 & 81,3 & 28 & 80,0 \\
\hline Madrugada & 12 & 36,4 & 3 & 9,4 & 1 & 2,9 \\
\hline
\end{tabular}

De seguida, questionou-se sobre se a insegurança em Coimbra tem vindo a aumentar. Os resultados são bastantes explícitos e encontram-se representados no Quadro II.

Salienta-se a perceção em todos os grupos etários, de que a insegurança tem vindo a aumentar. De facto $87 \%$ dos jovens e $97 \%$ dos idosos consideram que a insegurança na cidade de Coimbra tem vindo a aumentar.

Considerando que os espaços percecionados como inseguros se caracterizam não só pela sua territorialidade, mas também pela sua sazonalidade, tentouse saber qual é o período de dia em que os inquiridos se sentiam mais inseguros em Coimbra (Quadro II).

Todos os grupos etários são unânimes na opinião de que o período do dia em que se sentem mais inseguros é durante a noite. No entanto, para os adultos e idosos os períodos da tarde e da manhã já são considerados como períodos do dia inseguros. Os jovens, ao contrário dos adultos e idosos, consideram a madrugada insegura, algo que se prende com as vivências durante este período. Esta interpretação está relacionada sobretudo com a frequência de espaços e os hábitos de saída de casa em determinado período do dia.
Analisando a perceção da insegurança na cidade de Coimbra, numa outra questão efetuada aos inquiridos questionámos sobre a territorialidade da insegurança. Ora, os lugares foram referidos pelos inquiridos, dado que se tratava de uma questão aberta.

Os lugares referidos como inseguros foram: Alta, Arcos do Jardim, Baixa, Bota Abaixo, Calhabé, Casa do Sal, Celas, Conchada, Eiras, Fernão de Magalhães, Ingote, Jardim da Sereia, Lordemão, Loreto, Pedrulha, Quinta de São Jerónimo, Rua da Sofia e Santa Clara (Figura 4).

A análise pretendeu ilustrar não só as territorialidades da insegurança em Coimbra, mas também o grupo etário que escolheu determinado lugar como inseguro.

Da análise da figura 4 salienta-se que os resultados obtidos foram muito diversificados. No entanto, assistiu-se a uma tendência para determinados lugares. Destaca-se a área da Baixa como o lugar que mais inquiridos referiram, por todos os grupos etários, sobretudo os idosos. Também o Bairro do Ingote foi referido por muitos inquiridos, principalmente pelos jovens.

Perante este cenário de perceção das áreas inseguras da cidade, é pertinente saber se os inquiridos deixam de ir a algum local e se evitam ir a determinada área, por questões de segurança (Quadro III).

Verifica-se que uma grande parte dos inquiridos não frequenta determinados locais por motivos de (in) segurança. Existe uma certa unanimidade nos locais evitados pelos inquiridos, sendo a Baixa e Bairro do Ingote os mais referidos. 0 período do dia em que mais indivíduos evitam deslocar-se aos lugares por questões de in-

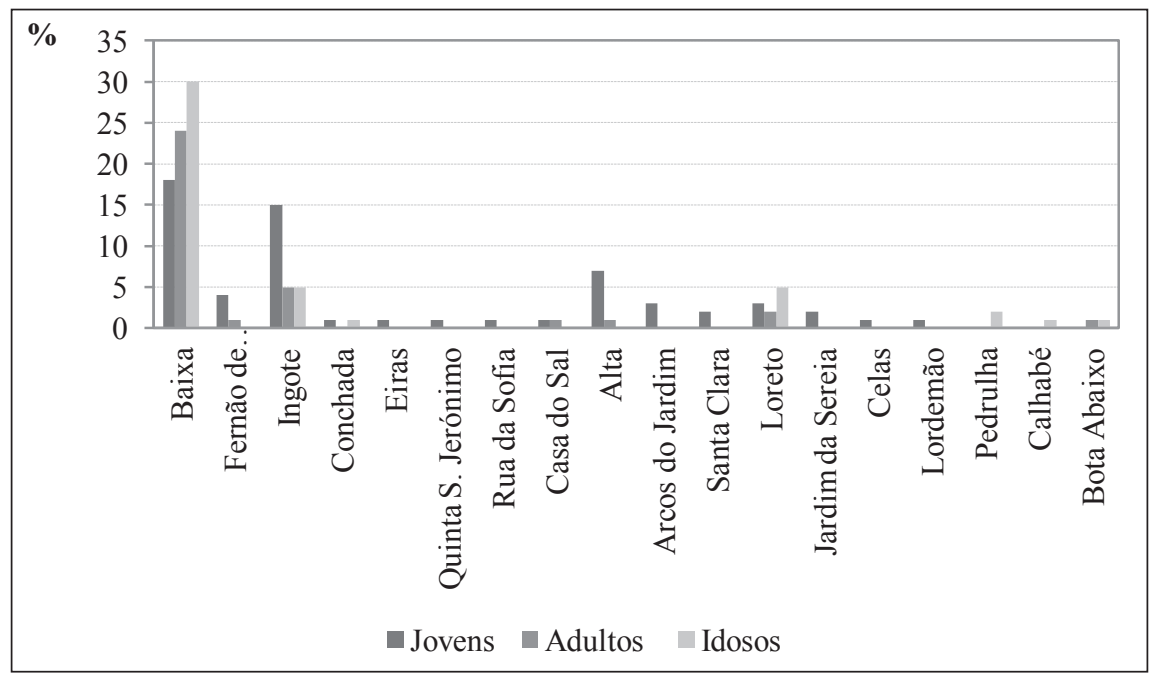

Figura 4

Perceção das áreas de insegurança da cidade de Coimbra, segundo os grupos etários. 
Quadro III

Locais evitados na Cidade de Coimbra

\begin{tabular}{|c|c|c|c|}
\hline \multicolumn{4}{|c|}{ "Evita algum local, em algum período do dia em Coimbra?" } \\
\hline Sim & Jovens & Adultos & Idosos \\
\hline Não & 16 & 12 & 17 \\
\hline \multicolumn{3}{|c|}{ "Se sim, quais e quando?" } \\
\hline Quais? & $\begin{array}{c}\text { Bairro do Ingote, Baixa, Av. } \\
\text { Fernão de Magalhães, Alta }\end{array}$ & $\begin{array}{c}\text { Baixa, Av. Fernão de Magalhães, Bairro } \\
\text { do Ingote, Santa Clara }\end{array}$ & Baixa, Santa Clara \\
\hline Quando? & Noite & Noite e em qualquer hora (Ingote) & $\begin{array}{c}\text { Noite e a qualquer } \\
\text { hora (Baixa) }\end{array}$ \\
\hline
\end{tabular}

segurança é o período noturno, embora existam respostas de indivíduos condicionados a determinados locais a qualquer hora, como por exemplo, no caso dos adultos, o Bairro do Ingote e no caso dos idosos, a Baixa.

Como já se viu no Quadro III, é durante a noite que os inquiridos se sentem mais inseguros, salientando-se, também que evitam frequentar determinados espaços neste período. Assim, pareceu-nos interessante questionar os inquiridos se saem à noite, para que locais e se se sentem seguros para onde vão (Figura 5).

Como seria expectante, são os jovens que saem mais durante a noite, cerca de $91 \%$, enquanto que apenas $9 \%$ dos idosos afirmaram sair neste período. Numa outra questão, tentamos averiguar quais os locais frequentados e se os indivíduos sentem segurança nessas deslocações. Deste modo os jovens mencionam a Praça da Republica como local de eleição, embora a Alta, a Solum e Santa Clara recebam também as suas escolhas. Importa destacar que $80 \%$ dos jovens admite que se sente seguro para onde vai, sendo que $20 \%$ dos inquiridos deste grupo etário sentem-se inseguros nas suas saídas noturnas.

Os adultos deslocam-se sobretudo para a Praça da República, para a Alta, Sé Velha, Solum e Santa Clara, e a grande maioria sente segurança nos espaços que frequenta.

Por último, os idosos que saem no período noturno admitem fazê-lo para os centros comerciais "Dolce

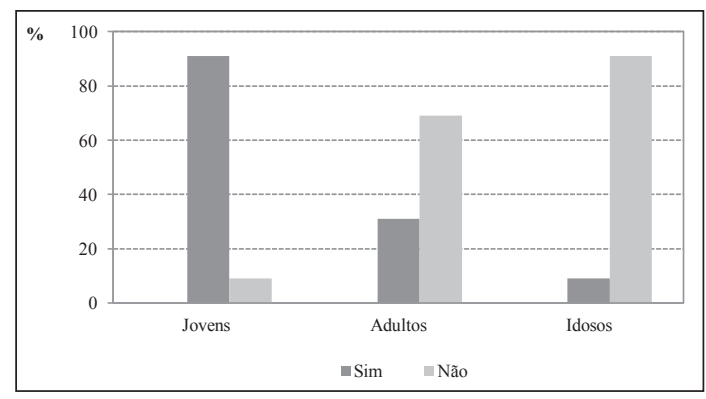

Figura 5

Habitualidade de saídas no período da noite.
Vita" e Fórum de Coimbra e sentem-se seguros para onde vão.

Neste seguimento, procurámos saber se os inquiridos já tinham sido vítimas de algum tipo de crime. Em relação ao grupo etário dos jovens, 14 inquiridos (44\% dos jovens) referiram que já foram alvo de algum tipo de crime. No grupo etário dos adultos, apenas 4 inquiridos foram vítimas de crime e 12 idosos foram alvo de crime.

Esta pequena amostra comprova uma maior vulnerabilidade dos jovens e idosos para a vitimização do crime.

Não esqueçamos que são dados que têm de ser interpretados à luz da observação de que se realizaram apenas 100 inquéritos, numa cidade com cerca de 143396 habitantes, segundo dados provisórios dos Censos 2011.

Em relação ao tipo de crime, além de diversificados, há que salientar a ocorrência de roubos e assaltos em todos os grupos etários.

As ocorrências de crimes, classificando-se pelo seu tipo estão representadas no Quadro IV, e na figura 6 encontram-se cartografadas as áreas nas quais os inquiridos sofreram os crimes.

Assim, o grupo etário que regista maior número de ocorrências de crime é o dos jovens, seguidos dos idosos e finalmente, dos adultos. No que concerne à tipologia dos crimes salienta-se a ocorrência de muitos assaltos, seja à pessoa, à residência, ao local de trabatho, ou mesmo ao automóvel. Registou-se também um sequestro e uma perseguição.

Os locais onde ocorreram os crimes correspondem alguns deles às áreas que os inquiridos consideram ser as mais inseguras, como a Baixa, Arcos do Jardim, Alta e Bairro do Loreto. No entanto, observam-se também ocorrências em áreas percecionadas como "mais calmas, mais seguras", tais como o Vale das Flores e a Solum.

Quanto ao período do dia no qual se realizaram a maioria das ocorrências dos crimes, temos sem dúvida o 
Quadro IV

Inquiridos vítimas de crimes

\begin{tabular}{|c|c|c|}
\hline \multicolumn{3}{|c|}{ "Qual foi o crime que foi alvo?" } \\
\hline Jovens & Adultos & Idosos \\
\hline $\begin{array}{c}\text { Perseguição (1) } \\
\text { Tentativa de assalto (5) } \\
\text { Assalto a residência (2) } \\
\text { Sequestro (1) } \\
\text { Roubo (6) } \\
\text { Assalto a automóvel (2) }\end{array}$ & $\begin{array}{c}\text { Assalto ao local de trabalho (1) } \\
\text { Roubo (3) }\end{array}$ & $\begin{array}{l}\text { Assalto (6) } \\
\text { Assalto a residência (3) } \\
\text { Tentativa de assalto (2) } \\
\text { Assalto a automóvel (1) }\end{array}$ \\
\hline \multicolumn{3}{|c|}{ "Onde ocorreu o crime?" } \\
\hline $\begin{array}{l}\text { Jardim da Sereia, Couraça de Lisboa, } \\
\text { HUC, Alta, Celas, Eiras, Arcos do Jardim, } \\
\text { Solum, Loreto, Elevador do Mercado }\end{array}$ & Baixa, Mercado, Vale das Flores & Vale das Flores, Baixa, Alta, Celas \\
\hline \multicolumn{3}{|c|}{ "Em que período do dia ocorreu?" } \\
\hline $\begin{array}{l}\text { Noite (11) } \\
\text { Tarde (3) }\end{array}$ & $\begin{array}{l}\text { Manhã (3) } \\
\text { Tarde (1) }\end{array}$ & $\begin{array}{l}\text { Manhã (2) } \\
\text { Tarde (2) } \\
\text { Noite (8) }\end{array}$ \\
\hline
\end{tabular}

período noturno, existindo também ocorrências registadas durante o dia, tanto de manhã como à tarde.

De facto, as ocorrências do crime não se realizam só nas áreas que os inquiridos percecionam como inseguras, e não foi só no período noturno que se registaram crimes.

De seguida, de uma lista de doze lugares: Alta, Avenida Fernão de Magalhães, Bairro Norton de Matos e Vale das Flores, Celas, Eiras, Ingote, Praça da República e Avenida Sá da Bandeira, Pólo II, Santa Clara e Solum, solicitou-se aos inquiridos que classificassem estes lo- cais numa escala de 1 a 5 , em que o 1 significava Seguro e o 5 Extremamente Inseguro (Figura 7). Após o tratamento estatístico dos inquéritos procedeu-se a uma média para cada lugar. Assim, o valor mínimo obtido é 2 (Pouco inseguro), seguido de 3 (Inseguro), 4 (Muito inseguro), e 5 (Extremamente inseguro).

O local considerado mais perigoso foi a Baixa da cidade, seguindo-se-lhe o Bairro do Ingote, Pedrulha e Eiras.

De facto, a imagem associada a bairros sociais, como é o caso do Ingote, corresponde a lugares de mar-

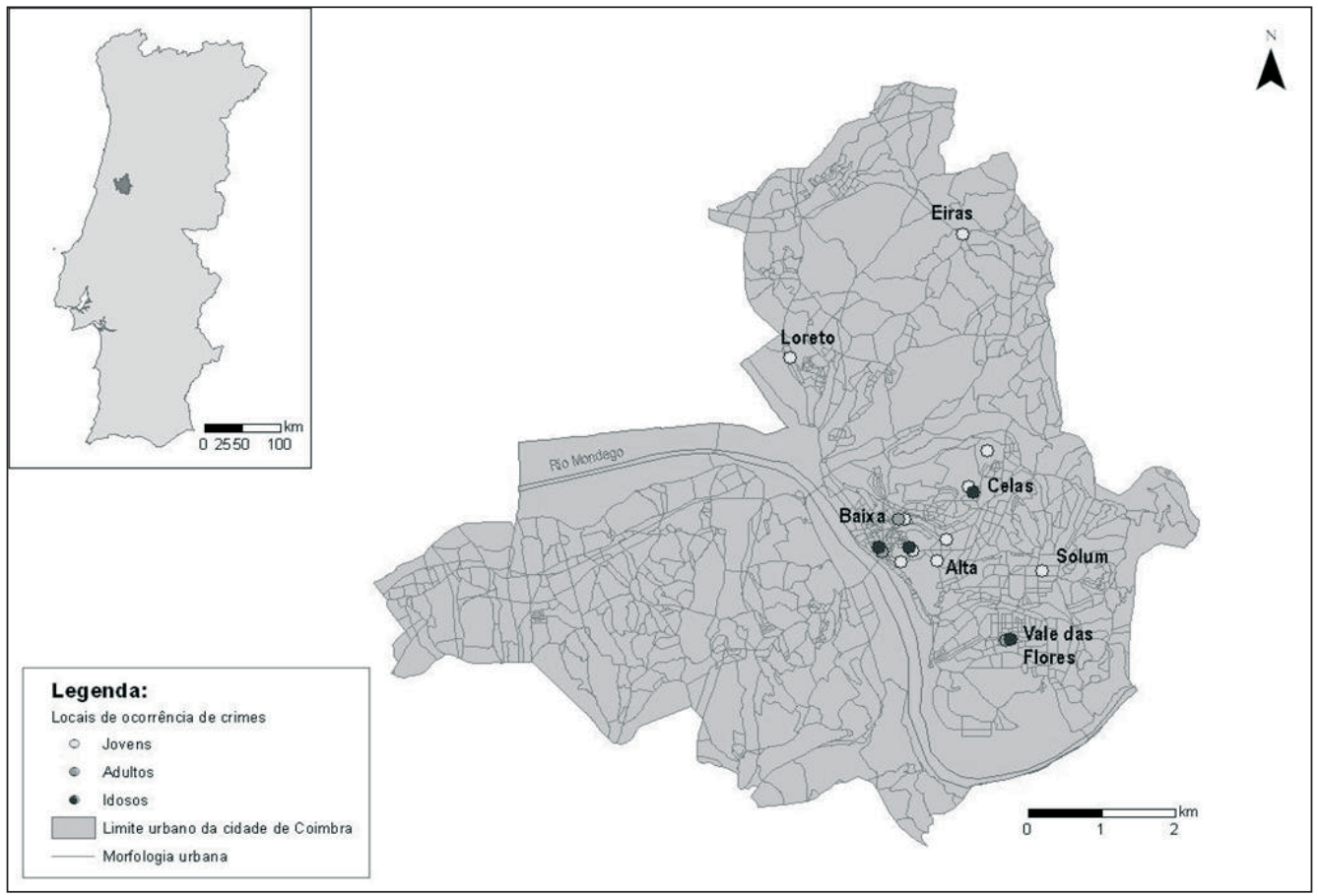

Figura 6

Locais de ocorrência dos crimes dos inquiridos. 
ginalidade e degradação social, pelo que muitos indivíduos referiram que evitam deslocar-se a estes espaços. De facto, a imagem mental acaba por condicionar as deslocações, aumentar os sentimentos de insegurança e evitar passar em determinados lugares.

Em relação à área central da cidade, a imagem negativa é alimentada pelos diálogos mantidos com amigos, familiares, vizinhos, e meios de comunicação que propagam relatos de algumas ocorrências criminais nesta área. Neste caso a imagem torna-se mais negativa à medida que a noite chega e a Baixa se despovoa.

\section{Conclusão}

Numa fase inicial, o objetivo deste estudo, recaía sobre dois aspetos essenciais: a perceção da população sobre a insegurança, territorializando as áreas percecionadas como mais inseguras e a localização das áreas onde, de facto, ocorrem um maior número de crimes. Para cumprir este segundo objetivo contactámos a Policia de Segurança Pública, que nos negou o fornecimento de dados. 0 nosso objetivo ficou assim restrito à perceção da população sobre a insegurança na cidade de Coimbra.

Assim, realizaram-se inquéritos a fim de avaliar a perceção dos indivíduos que residem na cidade de Coimbra. As respostas exprimem que o sentimento de insegurança tem vindo a aumentar, as pessoas sentemse mais inseguras, sendo que este sentimento não se restringe apenas durante a noite. Aliás, das ocorrências de crimes registados destaca-se o facto de, nos grupos etários dos adultos e idosos, a maioria dos crimes se ter registado durante o dia.

Quanto aos sentimentos de insegurança vividos pelos inquiridos, são distintos consoante o sexo, a idade, a ocupação profissional, o estatuto socioeconómico, sendo as mulheres aquelas que revelaram maiores preocupações relativamente a estes riscos urbanos. Os locais e as circunstâncias influenciam também as sensações de insegurança, pois, de um modo geral, os inquiridos mostraram sentir mais receio à noite do que durante o dia, sendo os espaços mais temidos as ruas pouco movimentadas, os bairros periféricos e as áreas frequentadas por indivíduos marginais.

As áreas que os inquiridos consideram ser as mais inseguras são a Baixa, a Avenida Fernão de Magalhães e

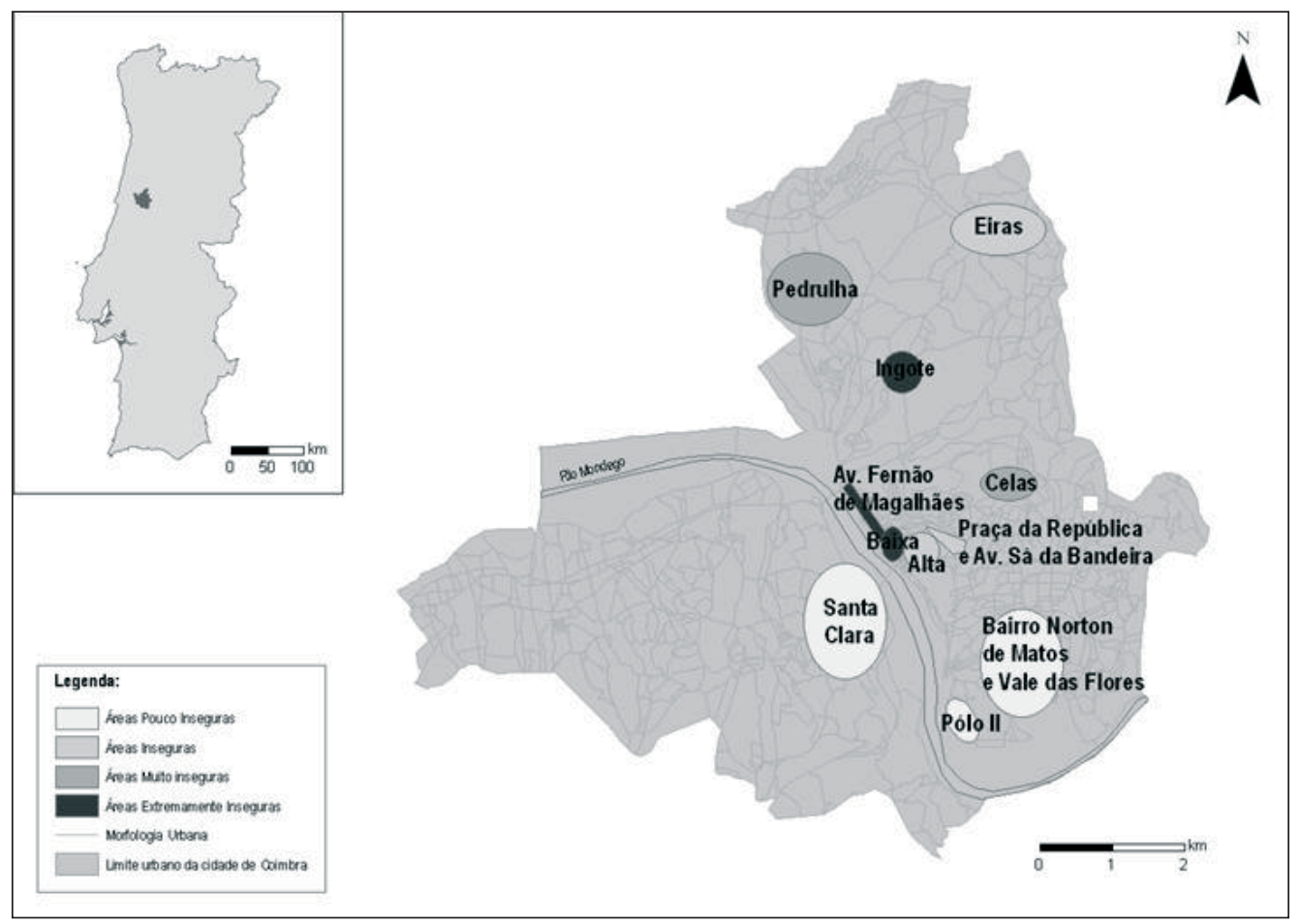

Figura 7

Áreas inseguras na cidade de Coimbra, de acordo com a perceção dos inquiridos. 
o Bairro do Ingote. O sentimento de insegurança generalizado, o tráfico e consumo de drogas e a prostituição são as razões apontadas para este sentimento de receio e insegurança.

No final deste trabalho fica a sensação de que a imagem mental que um indivíduo tem de determinada área vai condicionar o seu comportamento no espaço, podendo mesmo chegar a evitar a frequência do lugar ou a simples passagem pelo mesmo. Saliente-se que, em alguns casos a imagem mental não corresponde à imagem real. Assim, ainda que neste trabalho não tenha sido possivel fazer o apuramento destas estatísticas, é importante decifrar as perceções porque estas condicionam os comportamentos e estes os espaços geográficos.

\section{Bibliografia}

Bauman, Zygmunt (2006) - Confiança e medo na cidade. Relógio d’Água, Lisboa.

DıNız, A. M. A. (2003) - "A geografia do medo, reflexões sobre o sentimento de insegurança em Belo Horizonte". O Alferes, v. 18, Belo Horizonte, pp 119-133.

EsteVES, Alina (1995) - A criminalidade urbana e a perceção do espaço na cidade de Lisboa: uma geografia da insegurança. Tese de mestrado em Geografia Humana e Planeamento Regional e Local, Faculdade de Letras da Universidade de Lisboa, Lisboa.

EsteVEs, Alina (1999) - A criminalidade na cidade de Lisboa: uma geografia da insegurança. Colibri, Lisboa.
FelIX, Sueli (2002) - Geografia do crime: interdisciplinaridade e relevâncias. Marília: Unesp, Marília-Publicações, São Paulo.

Ferreira, Eduardo (1998) - Crime e insegurança em Portugal: padrões e tendências, 1985-1996. Celta Editora, Oeiras.

GASPAR, Jorge (1987) - Portugal - os próximos 20 anos. Ocupação e organização do espaço. Retrospectiva e tendências, vol.1, Fundação Calouste Gulbenkian, Lisboa.

IMBERT (1992) - Los escenários de la violência. Icaria Editorial, Barcelona.

KASHIWAGI, Helena (2004) - O processo de perceção e apropriação do espaço nas comunidades marginais urbanas: o caso da Favela do Parolin em Curitiba. Tese de Mestrado em Geografia, Universidade Federal do Paraná, Paraná.

MANGAS, Francisco (1997) - Geografia do medo. Teorema, Lisboa. NeIL, William J. V. (2001) - "Marketing the Urban Experience: Reflections on the Place of Fear in the Promotional Strategies of Belfast, Detroit and Berlim". Urban Studies, 38, 5-6, pp. 815-828.

PEIXoto, Alberto (2003) - Criminalidade e motivação: o caso de Ponta Delgada: perspectiva sociológica. Blu edições, Angra do Heroísmo.

Santana, Paula e Roque, Nuno (2007) - "A (In)Segurança na Amadora". In: Santana, Paula Santana, Paula (Org.) A Cidade E A SAÚDE. Almedina, Coimbra, pp.182-195.

Tuan, Yi-fu (1980) - Topofilia: um estudo da perceção, atitudes e valores do meio ambiente. Difel, São Paulo.

WikströM, P. O. (1990) - "Delinquency and the urban structure". In: Wikstrom, Per-Olof (ed.) Crime and measures against crime in the city. National Council for Crime Prevention. Sweden, pp. 7-30. 